\title{
Alimentação de quatro espécies de Characiformes de um riacho da Floresta Atlântica, Guaraqueçaba, Paraná, Brasil ${ }^{1}$
}

\author{
Almir P. Barreto ${ }^{2} \&$ José M. R. Aranha ${ }^{3}$ \\ ${ }^{1}$ Contribuição número 1651 do Departamento de Zoologia, Universidade Federal do Paraná. \\ 2 Pontifícia Universidade Católica do Paraná. Campus Toledo, Avenida da União 500, Jardim Coopagro, 85902-532 Toledo, \\ Paraná, Brasil. E-mail: almirbarreto@pucpr.br \\ ${ }^{3}$ Laboratório de Ecologia de Rios, Departamento de Zoologia, Universidade Federal do Paraná. Caixa Postal 19020, \\ 81531-980 Curitiba, Paraná, Brasil.E-mail: jmaranha@ufpr.br
}

\begin{abstract}
Diet of four species of Characiforms in an Atlantic Forest stream, Guaraqueçaba, Paraná, Brazil. In the present study we analyzed seasonal changes in the diet, feeding behavior and food resource partitioning between juveniles and adults of four characiform species in an Atlantic Rainforest stream of the northern coast of the State of Paraná, Brazil. Samples were collected monthly between September, 1999 and August, 2000 using a variety of capture techniques and underwater observations. In general, full stomach contents were more common in juveniles than in adults. Deuterodon langei Travassos, 1957 was classified as an omnivorous species, with a tendency toward herbivory, Characidium lanei Travassos 1967 was classified as an insectivore, with a tendency toward larvophagy, Hyphessobrycon griemi Hoedeman, 1957 was classified as an omnivore, and Mimagoniates microlepis Steindachner, 1876 was classified as an insectivore, with a predominance of allochtonous insects. Juveniles and adults of all studied species showed low selectivity and high opportunism in their food selection. The high frequency of allochtonous food items in stomach contents underscores the importance of marginal vegetation in their diets, being essential for the integrity of these environments and for the preservation of coastal stream fish communities.

KEY WORDS. Coastal stream fishes; diet; feeding behavior; food partitioning.
\end{abstract}

RESUMO. No presente estudo foram analisadas mudanças sazonais na dieta, comportamento alimentar e partilha de recursos de jovens e adultos de quatro espécies de Characiformes em um riacho de Floresta Atlântica, localizado no norte do litoral paranaense. As coletas foram realizadas mensalmente entre agosto de 1999 e setembro de 2000 com a utilização de técnicas tradicionais de pesca e observações subaquáticas diretas. A análise da dieta foi realizada através do método de frequiência de ocorrência. Em geral, exemplares jovens apresentaram frequiências de estômagos repletos superiores aos adultos. Deuterodon langei Travassos, 1957 foi considerado onívoro com tendência à herbivoria, Characidium Ianei Travassos, 1967 foi considerado insetívoro aquático com tendência à larvofagia, Hyphessobrycon griemi Hoedeman, 1957 como onívoro, e Mimagoniates microlepis (Steindachner, 1876) foi considerado insetívoro com predominância de insetos alóctones na dieta. Jovens e adultos das quatro espécies apresentaram baixa seletividade e alto oportunismo na obtenção de alimento. As altas freqüências de itens alóctones encontradas na dieta demonstraram a importância da vegetação marginal como fonte de recursos, sendo fundamental para o equilíbrio desses ecossistemas e manutenção dessas comunidades.

PALAVRAS-CHAVE. Comportamento alimentar, dieta, partilha de recursos, peixes de riacho.

A alimentação é um dos mais importantes aspectos da bionomia das espécies, interferindo diretamente na estrutura e composição de populações. O conhecimento da dieta, táticas alimentares e estrutura trófica são fundamentais para a compreensão da dinâmica das comunidades e para conservação dos ecossistemas.

Estudos sobre alimentação de peixes de riacho versam principalmente sobre a estrutura trófica de assembléias e partilha de recursos entre determinadas espécies de um mesmo local (e.g. Arcifa et al. 1991, Aranha et al. 1998, Resende 2000, Hahn et al. 2004), sobre a dieta das espécies (e.g. Vilella et al. 2002, LAMPERT et al. 2003), sobre as táticas alimentares (e.g. SAzImA 1986, Costa 1987, SABINO \& ZUANON 1998) e sobre as variações ontogenéticas na dieta de uma espécie (e.g. Vitule \& Aranha 2002).

Lowe-McConnell (1987) postula que, em geral, peixes de regiões tropicais não apresentam especializações tróficas, mo-

Revista Brasileira de Zoologia 23 (3): 779-788, setembro, 2006 
dificam sua dieta conforme o crescimento, mudanças de biótopo ou de acordo com flutuações estacionais. Esta sazonalidade é induzida principalmente por mudanças no nível d'água que afetam o habitat e conseqüentemente a disponibilidade de alimento (Winemiller \& Jepsen 1998, Aranha et al. 2000). Mesmo considerando que a ação desestabilizadora de fatores físicos do ambiente passam a manter as populações abaixo da capacidade suporte do meio, diminuindo a competição por alimento (WIENs 1977). Ainda assim, alguns autores acreditam que a partilha de recursos nestes ambientes é um importante fator ecológico para redução da competição entre as espécies, permitindo sua coexistência (e.g. Aranha et al. 1998).

Este trabalho teve como objetivo analisar sazonalmente o grau de repleção, dieta, comportamento alimentar e a partilha de recursos de jovens e adultos de Deuterodon langei Travassos, 1957, Mimagoniates microlepis (Steindachner, 1876), Characidium lanei Travassos, 1967 e Hyphessobrycon griemi Hoedeman, 1957 no rio Morato.

\section{MATERIAL E MÉTODOS}

\section{Área de estudo}

O estudo foi realizado no rio Morato, bacia do Leste, dentro da Reserva Natural Salto Morato (RNSM), aproximadamente $25^{\circ} 10^{\prime} \mathrm{S}, 48^{\circ} 18^{\prime} \mathrm{W}$. Esta reserva está situada dentro da Área de Proteção Ambiental de Guaraqueçaba, região norte do litoral do Estado do Paraná, e é considerado um dos mais significativos remanescentes de Floresta Ombrófila Densa quanto ao estado de conservação.

O rio Morato, com aproximadamente $10 \mathrm{~km}$ de extensão, nasce na vertente leste da Serra do Mar, percorre a planície litorânea e deságua no rio Guaraqueçaba, próximo à sua foz na Baía de Guaraqueçaba. O trecho estudado é considerado um riacho de terceira ordem (Suguio \& Bigarella 1990), não sofre influência de marés, suas águas são cristalinas, com pH levemente ácido e temperaturas variando entre 12 e $22^{\circ} \mathrm{C}$ (Fig. 1).

\section{Métodos}

O estudo da alimentação foi realizado através da determinação do grau de repleção, da análise dos conteúdos estomacais e da descrição das táticas alimentares de jovens e adultos das quatro espécies em cada estação do ano. As amostragens realizadas entre 22 de dezembro a 19 de março foram consideradas da estação verão, os exemplares coletados entre 20 de março e 19 de junho foram consideradas da estação outono, de 20 de junho a 22 de setembro do inverno e de 23 de setembro a 21 de dezembro da estação primavera.

A análise do grau de repleção e da dieta foi realizada com exemplares coletados mensalmente entre agosto de 1999 e setembro de 2000. As coletas foram realizadas nos mais variados ambientes ao longo da área de estudo (e.g. corredeiras, remansos, rápidos), utilizando redes de espera com malhas 1,5 e 2,5 cm entre nós consecutivos durante 48 horas de exposição, com despescas realizadas no início das manhãs e final da tarde, tarrafa malha $1,0 \mathrm{~cm}$ com $1,5 \mathrm{~m}$ de diâmetro, peneiras malha $0,5 \mathrm{~cm}$, e uma rede com $2 \mathrm{~mm}$ de malha e $2 \mathrm{~m}$ de comprimento para realização de arrastões.

Os peixes capturados foram fixados em formalina a $10 \%$ imediatamente após a captura e transferidos para álcool a 70\% em laboratório, para posterior identificação e dissecção. Os exemplares foram identificados utilizando chaves de identificação e através de comparações com exemplares depositados no Museu de História Natural do Capão da Imbúia (MHNCI) e no Laboratório de Ecologia de Rios da Universidade Federal do Paraná. Os espécimes-testemunho estão depositados no Departamento de Zoologia da Universidade Federal do Paraná sob os números DZUP-PX27 a DZUP-PX40.

Em laboratório, os peixes foram medidos, pesados e dissecados, sendo considerados jovens aqueles exemplares com gônadas no estádio imaturo, e como adultos os exemplares com gônadas em maturação, maduras, desovadas e em recuperação.

Quando possível, 15 jovens e 15 adultos de cada espécie e de cada estação do ano foram utilizados para a determinação do grau de repleção estomacal e análise da dieta.

O grau de repleção estomacal foi definido considerando grau 3 para estômagos com 100\% do volume repleto, 2 para estômagos com 50\% do volume ocupado com alimento, 1 para estômagos com $10 \%$ da sua capacidade repleta e 0 para estômagos completamente vazios (baseado em ZaVALA-CAMIN 1996).

A dieta foi definida através da análise do conteúdo estomacal de jovens e adultos em relação às estações do ano. Os itens alimentares foram identificados com auxílio de microscópio estereoscópico e microscópio óptico, ao menor nível taxonômico possível, com auxílio de chaves de identificação (Chu 1949, Bicudo \& Bicudo 1970, McCafferty 1981, STehr 1987, Borror \& Delong 1988, Péres 1988, Lopreto \& Tell 1995).

Após a identificação dos itens alimentares, foi utilizado o método de freqüência de ocorrência baseado em HysLop (1980). A amplitude do nicho de jovens e adultos das quatro espécies foi determinada através do índice de Shannon-Wiener calculado com auxílio do software Ecological Methodology (KreBs 1989) e as semelhanças entre as dietas de cada espécie em cada estação do ano e de jovens e adultos foram determinadas através da análise de agrupamento UPGMA, com auxílio do programa estatístico NTsys, versão 5.0, utilizando o coeficiente de similaridade de Morisita modificado por HoRN (1966). Para a análise da dieta os itens foram agrupados em categorias da seguinte forma: algas unicelulares; algas filamentosas; vegetais superiores (briófita, raiz, caule, folha, flor, fruto e semente); Nematoda; Oligochaeta; Bivalvia; microcrustáceos (Cladocera, Isopoda, Amphipoda) e Decapoda; larvas autóctones (formas jovens de Ephemeroptera, Plecoptera, Odonata, Lepidoptera, Coleoptera, Trichoptera e Diptera); insetos autóctones; e insetos alóctones (Heteroptera, Coleoptera, Orthoptera, Hymenoptera, Thysanoptera e Lepidoptera); ovos; ácaros; Aranea; fragmentos de artrópodes; e detritos.

Para a descrição das táticas alimentares foram realizadas observações subaquáticas com o auxílio de máscara, snorkel, 


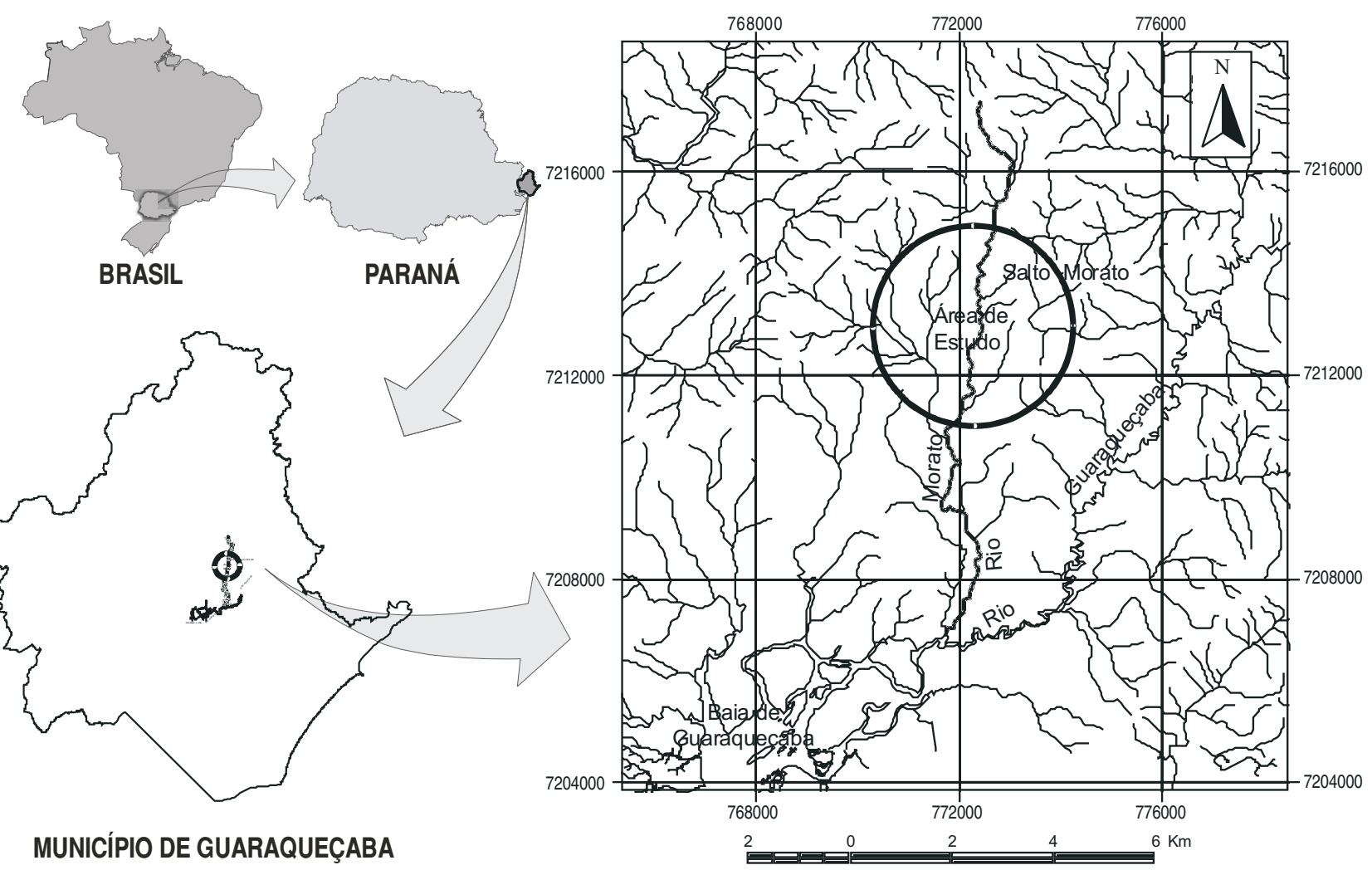

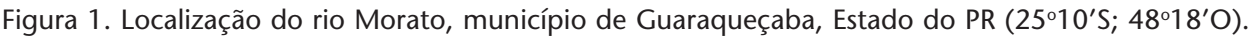

segundo as técnicas ad libitum e animal-focal (SABINo 1999). Os mergulhos foram realizados ao longo de todo trecho estudado, em horários variados, inclusive à noite com auxílio de lanterna estanque. Durante os mergulhos, foram registrados em placa de PVC dados referentes aos aspectos comportamentais como procura, localização, captura e ingestão dos alimentos. A determinação das categorias de forrageamento foi baseada em SAZIMA (1986).

\section{RESULTADOS}

\section{Grau de repleção}

Foram analisados no total 406 estômagos, distribuídos da seguinte forma: 119 de M. microlepis, 110 de D. langei, 98 de C. lanei e 79 de $H$. griemi. Não foram coletados exemplares jovens de $H$. griemi nas estações verão e inverno.

Quanto ao grau de repleção, exemplares jovens apresentaram porcentagem de estômagos repletos superior aos adultos, com exceção das amostras de $C$. lanei durante o inverno e H. griemi no outono. Os jovens de M. microlepis apresentaram, em geral, os maiores números de estômagos repletos. Exemplares jovens e adultos de C. lanei apresentaram o menor número de estômagos repletos, sendo freqüente estômagos com grau de repleção 1 e 2 (Figs 2 a 5).
Apenas D. langei e H. griemi apresentaram exemplares com estômagos vazios, adultos de $D$. langei no outono, inverno e primavera, jovens de $H$. griemi no verão e tanto jovens como adultos desta espécie durante a primavera (Figs 2 e 3).

A variação do grau de repleção para $D$. langei foi maior entre os jovens nas amostragens da primavera e verão e para adultos durante o outono (Fig. 2). Para jovens de C. lanei foi observada maior repleção na primavera e para adultos no verão (Fig. 4). Os jovens e adultos de M. microlepis apresentaram predominância de estômagos repletos nas amostragens das quatro estações, durante o inverno para adultos, foi observada um aumento nas freqüências de estômagos com graus de repleção $1 \mathrm{e}$ 2 (Fig. 5).

\section{Dieta}

Deuterodon langei foi considerado onívoro, apresentando 38 itens alimentares na sua dieta, sendo 17 itens para os jovens e 35 itens para os adultos. Esta espécie apresentou tendência a herbivoria, sendo as algas unicelulares e filamentosas os principais itens da dieta. Além das algas, os adultos apresentaram folhas e frutos e os jovens detritos nos conteúdos analisados. As formas jovens de insetos autóctones, principalmente de Diptera, insetos alóctones, principalmente himenópteros da família Formicidae e aranhas complementam a dieta desta es- 


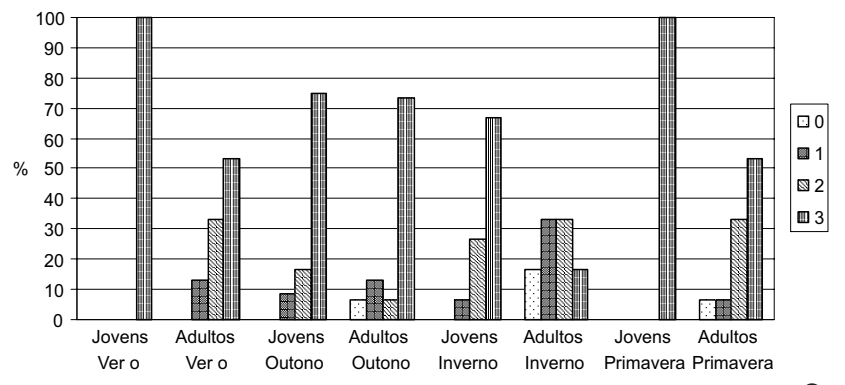

2

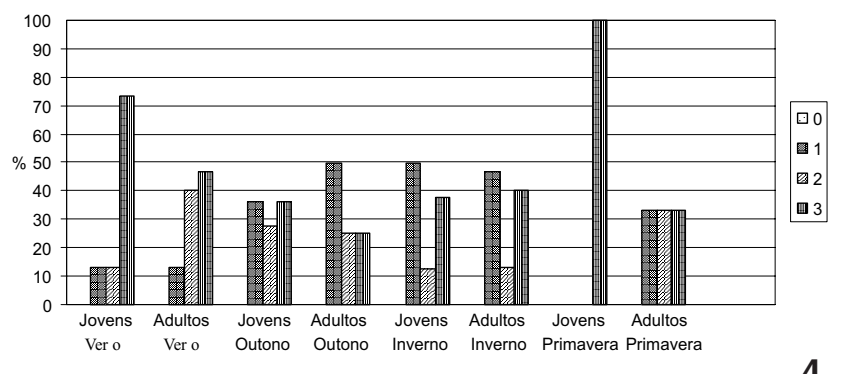

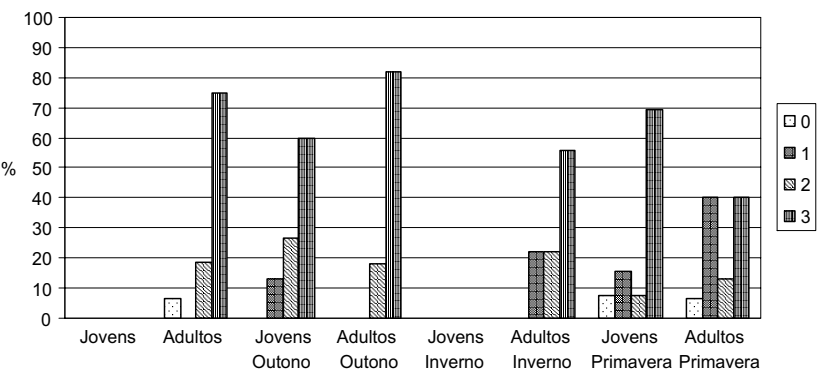

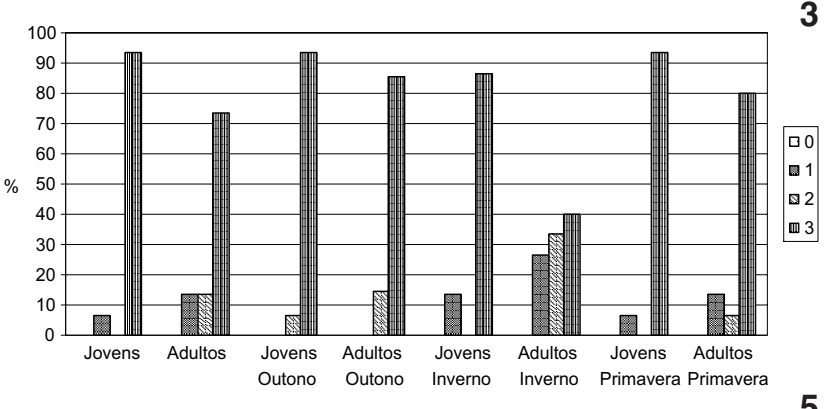

Figuras 2-5. Grau de repleção estomacal sazonal. (2) Deuterodon langei; (3) Hyphessobrycon griemi; (4) Characidium lanei; (5) Mimagoniates microlepis. Legenda: (0) estômago vazio, (1) estômago com 1/10 do volume com conteúdo, (2) estômago com metade do volume com conteúdo, (3) estômago repleto.

pécie. Quanto a sazonalidade foram observadas variações quantitativas na utilização dos recursos (e.g. maiores freqüências de larvas de Diptera entre os jovens durante o inverno; maiores freqüências de coleópteros terrestres entre os adultos na primavera e verão) (Tabs I e II).

Characidium lanei foi considerado insetívoro com tendência a larvofagia. Essa espécie apresentou 16 itens alimentares na sua dieta, sendo os adultos mais restritivos quanto à utilização dos recursos, com apenas 10 itens registrados. Com o predomínio de formas jovens aquáticas de insetos na dieta, as larvas de Diptera foram os itens que ocorreram com maiores freqüências, seguidas das ninfas de Ephemeroptera e larvas de Trichoptera. Os jovens foram mais generalistas, alimentandose ao longo do ano de invertebrados aquáticos como ácaros, crustáceos e nematódeos. A presença de itens de origem vegetal foi bastante rara (Tabs I e II).

Hyphessobrycon griemi foi considerado onívoro. Os adultos apresentaram 21 itens alimentares e os jovens 11 itens na dieta. Apesar dos jovens não terem sido capturados no verão e no inverno, nas amostras de outono e primavera foi possível observar diferenças na utilização dos recursos entre jovens e adultos. Apesar de ambos apresentarem altas freqüências de fragmentos de artrópodes, destaca-se o predomínio de insetos terrestres entre os adultos, principalmente de himenópteros Formicidae e coleópteros. Os jovens apresentaram altas freqüências de larvas de Diptera durante a primavera e algas filamentosas durante o outono (Tabs I e II).

Mimagoniates microlepis foi considerada insetívora terres- tre, os adultos apresentaram 36 itens na sua dieta, sendo 28 para os jovens e 27 para os adultos. Os insetos de origem alóctone, principalmente himenópteros Formicidae e coleópteros, foram predominantes em todas as estações do ano. Itens de origem vegetal e invertebrados autóctones foram raros, com exceção de formas jovens de insetos, principalmente larvas de Diptera, com maiores freqüências nos conteúdos estomacais dos jovens ao longo do ano (Tabs I e II).

Os jovens e adultos das quatro espécies apresentaram grande amplitude de nicho quanto à dieta, com índice de Shannon-Wiener variando de 0,72 (C. lanei - jovens) a 0,86 (H. griemi - jovens) (Fig. 6).

As espécies estudadas apresentaram baixa similaridade (26\%), com exceção de $H$. griemi, que em determinados estádios e épocas do ano apresentou maior similaridade com a dieta de outras espécies (e.g. jovens no outono com jovens de $D$. langei devido ao consumo de algas filamentosas, e adultos, com exceção da primavera, com M. microlepis, devido ao consumo de insetos alóctones).

Os exemplares de $H$. griemi da primavera apresentaram 91\% de similaridade na dieta devido às altas freqüências de fragmentos de artrópodes. C. lanei apresentou similaridade de 90\% devido ao consumo de larvas de insetos autóctones e $M$. microlepis de $88 \%$ devido ao consumo de insetos alóctones. Com $66 \%$ de similaridade, observou-se a formação de um agrupamento de adultos de $D$. langei do verão e primavera, consumidores de vegetais superiores e insetos alóctones, e outro agrupamento com os demais exemplares desta espécie que se ali- 
Tabela I. Distribuição sazonal da freqüência de ocorrência dos itens alimentares de Deuterodon langei, Characidium lanei. (Pri) Primavera, (Ver) verão, (I) jovens, (A) adultos.

\begin{tabular}{|c|c|c|c|c|c|c|c|c|c|c|c|c|c|c|c|c|}
\hline \multirow{3}{*}{ Itens alimentares } & \multicolumn{8}{|c|}{ D. langei } & \multicolumn{8}{|c|}{ C. lanei } \\
\hline & Ver & Pri & Ver & Pri & Ver & Pri & Ver & Pri & Ver & Pri & Ver & Pri & Ver & Pri & Ver & Pri \\
\hline & J & A & J & A & J & A & J & A & J & A & J & A & J & A & J & A \\
\hline Clorófita unicelular & 80,0 & & 80,3 & 60,0 & 80,0 & 53,3 & 100,0 & 20,0 & & & & & & & & \\
\hline Diatomácea & 100,0 & 26,7 & 100,0 & 80,0 & 100,0 & 80,0 & 100,0 & 46,7 & & & & & & & & \\
\hline Clorófita filamentosa & 80,0 & 40,0 & 100,0 & 46,7 & 100,0 & 93,3 & 100,0 & 66,7 & & & & & & & & \\
\hline Cianófita & 100,0 & 6,7 & 75,0 & 40,0 & 86,7 & 40,0 & 100,0 & 26,7 & & & & & & & & \\
\hline Briófita & & & & & & 6,7 & 20,0 & & & & & & & & & \\
\hline Raiz & & 6,7 & & & & & & 6,7 & & & & & & & & \\
\hline Caule & 20,0 & 20,0 & 8,3 & 13,3 & & 33,3 & & 26,7 & & & & & & & & \\
\hline Folha & & 20,0 & & 60,0 & & 26,7 & & 60,0 & & & & & & & & \\
\hline Flor & & 13,3 & & 6,7 & & 13,3 & & 20,0 & & & & & & & & \\
\hline Fruto & & 33,3 & & 33,3 & & 13,3 & & 33,3 & & & & & & & & \\
\hline Semente & & 13,3 & & 6,7 & & & & 26,7 & & & & & & & & \\
\hline Vegetal não identificado & & 20,0 & & & & & & 6,7 & & 13,3 & & & 12,5 & 6,7 & & \\
\hline Nematoda & & & & & & & & & 13,3 & & 9,1 & & & 6,7 & 7,1 & \\
\hline Oligochaeta & & & 8,3 & & & & & & 13,3 & & & & & & & \\
\hline Bivalvia & & & & & & & & & & & & & & & 7,1 & \\
\hline Araneae & & 6,7 & & 6,7 & & 6,7 & & 13,3 & & & & & & & & \\
\hline Acarina & & & & & & & & & & 13,3 & 9,1 & & 12,5 & 33,3 & 50,0 & 33,3 \\
\hline \multicolumn{17}{|l|}{ Isopoda } \\
\hline \multicolumn{17}{|l|}{ Amphipoda } \\
\hline Cladocera & & & & & & & & & 13,3 & & & & & 6,7 & 7,1 & \\
\hline Crustacea & & & & & & & & & & & 9,1 & & & & & \\
\hline Chilopoda & & & & & & 6,7 & & & & & & & & & & \\
\hline Pulpa de Ephemeroptera & & & & & & & & & & 6,7 & & & 25,0 & & & \\
\hline Ninfa de Ephemeroptera & & 13,3 & & & & & 6,7 & 20,0 & 86,7 & 53,3 & 18,2 & 25,0 & 25,0 & 33,3 & 64,3 & 66,7 \\
\hline \multicolumn{17}{|l|}{ Orthoptera } \\
\hline Larva de Plecoptera & & 6,7 & 16,7 & & & & 13,3 & & 6,7 & & & & & & 7,1 & \\
\hline \multicolumn{17}{|l|}{ Larva Odonata Anisoptera } \\
\hline \multicolumn{17}{|l|}{ Larva de Odonata } \\
\hline Larva de Coleoptera & & & & & & & & & 13,3 & & & & & 6,7 & & 33,3 \\
\hline \multirow{2}{*}{\multicolumn{17}{|c|}{ Ninfa de Hemiptera terrestre }} \\
\hline & & & & & & & & & & & & & & & & \\
\hline Hemiptera Gerridae & & 6,7 & & & & & & & & & & & & & & \\
\hline Hemiptera Corixidae & & 6,7 & & & & & & 6,7 & & & & & & & & \\
\hline Hemiptera terrestre & & 13,3 & & & & 6,7 & & 6,7 & & & & & & & & \\
\hline \multicolumn{17}{|l|}{ Larva de Homoptera } \\
\hline Ninfa de Homop. terrestre & & & & & & & & & & & & & & & & \\
\hline Homoptera & & & & & & & & & & & & & & & & \\
\hline Coleóptera terrestre & & 33,3 & & 20,0 & & 6,7 & & 46,7 & & & & & & & & \\
\hline Larva de Trichoptera & & & & & & 6,7 & & & 26,7 & 53,3 & 18,2 & 12,5 & 25,0 & 26,7 & 14,3 & 33,3 \\
\hline Larva de Lepid. Pyrralidae & & & & & & 6,7 & & & & & & & & & & \\
\hline Larva de Lepid. Noctuidae & 20,0 & & & & & & & 20,0 & & & & & & & 7,1 & \\
\hline Pulpa de Lepidoptera & & 6,7 & & & & & & & & & & & & & & \\
\hline Larva de Lepid. terrestre & & & & & & & & & & & & & & & & \\
\hline Lepidoptera & & & & & & & & & & & & & & & & \\
\hline Larva de Diptera & & 13,3 & 25,0 & 6,7 & 40,0 & 13,3 & 6,7 & 6,7 & 86,7 & 100,0 & 100,0 & 87,5 & 75,0 & 86,7 & 100,0 & 75,0 \\
\hline Pulpa de Dip. Chironomidae & & & & & 20,0 & & & & & & & & & & & \\
\hline Larva de Diptera Tipulidae & & & & & 6,7 & & & & & & & & & & & \\
\hline Pulpa de Diptera & & 6,7 & & & & & & & & & & & & & & \\
\hline Diptera terrestre & & 6,7 & & & & & & & & & & & & & & \\
\hline Larva de Neuroptera & & & & & & & & & & & & & & & & \\
\hline Hymenoptera & & 6,7 & & 13,3 & & & & 6,7 & & & & & & & & \\
\hline Formicidae & & 13,3 & 8,3 & 26,7 & & 13,3 & 6,7 & 13,3 & & & & & & & & \\
\hline Ovos & & & & 6,7 & & & & & & & & & & & & \\
\hline Fragmentos de Artropodes & & 33,3 & 33,3 & 6,7 & 53,3 & 6,7 & 6,7 & 40,0 & 26,7 & 33,3 & 27,3 & 25,0 & 12,5 & 6,7 & & 8,3 \\
\hline Detritos & 100,0 & 20,0 & 83,3 & 46,7 & 93,3 & 66,7 & 100,0 & 13,3 & & & & & & & & \\
\hline Escama & & & & & & & & 6,7 & & & & & & & & \\
\hline Mat.orgânica não identif. & & 13,3 & & & & 6,7 & & & & & & & & & & \\
\hline Total de estômagos & 5 & 15 & 12 & 15 & 15 & 15 & 15 & 15 & 15 & 15 & 11 & 8 & 8 & 15 & 14 & 12 \\
\hline
\end{tabular}

Revista Brasileira de Zoologia 23 (3): 779-788, setembro, 2006 
Tabela II. Distribuição sazonal da freqüência de ocorrência dos itens alimentares de Hyphessobrycon griemi e Mimagoniates microlepis. (Pri) Primavera, (Ver) verão, (J) jovens, (A) adultos.

\begin{tabular}{|c|c|c|c|c|c|c|c|c|c|c|c|c|c|c|}
\hline \multirow{3}{*}{ Itens alimentares } & \multicolumn{6}{|c|}{ H. griemi } & \multicolumn{8}{|c|}{ M. microlepis } \\
\hline & Ver & Pri & Ver & Pri & Ver & Pri & Ver & Pri & Ver & Pri & Ver & Pri & Ver & Pri \\
\hline & A & J & A & A & J & A & J & A & J & A & J & A & j & A \\
\hline $\begin{array}{l}\text { Clorófita unicelular } \\
\text { Diatomácea }\end{array}$ & & 6,7 & & & & & & & & & & & & \\
\hline $\begin{array}{l}\text { Diatomácea } \\
\text { Clorófita filamentosa }\end{array}$ & & & & & & & & & & & & & & 6,7 \\
\hline $\begin{array}{l}\text { Clorófita filamentosa } \\
\text { Cianófita }\end{array}$ & & $\begin{array}{l}53,3 \\
13,3\end{array}$ & 27,3 & 22,2 & & 6,7 & & & & 7,1 & & & & \\
\hline \multicolumn{15}{|l|}{ Briófita } \\
\hline \multicolumn{15}{|l|}{ Raiz } \\
\hline Caule & & & 9,1 & 11,1 & & & & & & & & & & \\
\hline \multicolumn{15}{|l|}{ Folha } \\
\hline Flor & & & & & & & & 6,7 & & & & & & \\
\hline Fruto & 6,7 & & & 11,1 & & & & & & & & & 13,3 & \\
\hline Semente & & & & & & & & & & & & 6,7 & & \\
\hline Vegetal não identificado & 6,7 & 20,0 & 27,3 & 11,1 & 7,7 & & & & & 7,1 & 6,7 & 13,3 & & 6,7 \\
\hline \multicolumn{15}{|l|}{ Nematoda } \\
\hline \multirow{2}{*}{\multicolumn{15}{|c|}{$\begin{array}{l}\text { Oligochaeta } \\
\text { Bivalvia }\end{array}$}} \\
\hline Bivalvia & & 20,0 & & & & & & & & & & & & \\
\hline Araneae & 6,7 & & 9,1 & & & 6,7 & 6,7 & 6,7 & & 7,1 & 20,0 & 6,7 & & 6,7 \\
\hline Acarina & & 26,7 & 27,3 & & 7,7 & 6,7 & & 6,7 & & & & & & \\
\hline Isopoda & 6,7 & & & & & 6,7 & 6,7 & & 7,1 & & 6,7 & & & \\
\hline Amphipoda & 13,3 & & & & & & & 6,7 & & & & & & \\
\hline \multicolumn{15}{|l|}{ Cladocera } \\
\hline \multicolumn{15}{|l|}{ Crustacea } \\
\hline \multirow{2}{*}{\multicolumn{15}{|c|}{$\begin{array}{l}\text { Chilopoda } \\
\text { Pulpa de Ephemeroptera }\end{array}$}} \\
\hline \multirow{2}{*}{\multicolumn{14}{|c|}{$\begin{array}{l}\text { Pulpa de Ephemeroptera } \\
\text { Ninfa de Ephemeroptera }\end{array}$}} & \\
\hline Ninfa de Ephemeroptera & 6,7 & & & & & & & & & & & & & \\
\hline Orthoptera & & & & & & & & & & & 13,3 & & & 6,7 \\
\hline Pulpa de Plecoptera & & & & & & & & 6,7 & & & 6,7 & & 6,7 & 6,7 \\
\hline Larva de Plecoptera & 6,7 & & & 11,1 & 7,7 & & & & & & & & & \\
\hline Larva Odonata Anisoptera & & & & & & & 6,7 & & & & & & & \\
\hline Larva de Odonata & & & & & & & 6,7 & & & & & & & \\
\hline Larva de Coleoptera & & & & & & & 20,0 & 13,3 & 13,3 & & & & 6,7 & 6,7 \\
\hline Thysanoptera & & & & & & & & & & & & & & \\
\hline Ninfa de Hemiptera terrestre & & & & & & & & & & & 6,7 & & 6,7 & \\
\hline Hemiptera Gerridae & & & & & & & & & & & & & & \\
\hline Hemiptera Corixidae & & & & & & & & & & & & & & \\
\hline Hemiptera terrestre & & & 9,1 & 11,1 & & & 13,3 & 13,3 & 6,7 & 7,1 & 13,3 & 20,0 & 6,7 & \\
\hline Larva de Homoptera & & & & & & & 6,7 & & & & & & & \\
\hline Ninfa de Homop. terrestre & 6,7 & & & & & & & & & & & & & 6,7 \\
\hline Homoptera & & & & & & & 13,3 & & & 7,1 & 46,7 & 6,7 & 6,7 & 6,7 \\
\hline Coleóptera terrestre & 33,3 & 6,7 & 9,1 & 44,4 & 7,7 & & 66,7 & 60,0 & 33,3 & 35,7 & 26,7 & 53,3 & 66,7 & 33,3 \\
\hline Larva de Trichoptera & & & & 11,1 & & & 13,3 & & & 14,3 & & & & \\
\hline Larva de Lepid. Pyrralidae & & & & & & & & & & & & & & \\
\hline Larva de Lepid. Noctuidae & & & & & & & & & 13,3 & & 6,7 & & 13,3 & \\
\hline Pulpa de Lepidoptera & & & & & & & 6,7 & & & 7,1 & 6,7 & & & \\
\hline Larva de Lepid. terrestre & 6,7 & & & & & & 13,3 & & 13,3 & 7,1 & & 13,3 & 6,7 & \\
\hline Lepidoptera & & & & & & & & 6,7 & & & & & & \\
\hline Larva de Diptera & 13,3 & & 9,1 & 22,2 & 53,8 & 33,3 & 20,0 & & 60,0 & 21,4 & 46,7 & 6,7 & 53,3 & 13,3 \\
\hline $\begin{array}{l}\text { Pulpa de Dip. Chironomidae } \\
\text { Larva de Diptera Tipulidae }\end{array}$ & & & & & & & & 6,7 & 20,0 & & & & & \\
\hline Pulpa de Diptera & & & & & & & 6,7 & 6,7 & 13,3 & 14,3 & 46,7 & & 13,3 & 6,7 \\
\hline Diptera terrestre & 26,7 & & 18,2 & & & & 13,3 & 6,7 & 6,7 & 7,1 & 40,0 & 26,7 & 13,3 & 6,7 \\
\hline Larva de Neuroptera & & & & & & & & & 6,7 & & 6,7 & & & \\
\hline Hymenoptera & & & 18,2 & & & & 6,7 & & 6,7 & 28,6 & & 33,3 & & 6,7 \\
\hline Formicidae & 73,3 & & 45,5 & 33,3 & & 6,7 & 66,7 & 13,3 & 46,7 & 57,1 & 40,0 & 13,3 & 60,0 & 46,7 \\
\hline Ovos & & & & & & 20,0 & 20,0 & 33,3 & 46,7 & 42,9 & 40,0 & 46,7 & 60,0 & 33,3 \\
\hline Fragmentos de Artropodes & 46,7 & 53,3 & 45,5 & 55,6 & 76,9 & 66,7 & & & & & & & & \\
\hline Detritos & 6,7 & 40,0 & 9,1 & & & & & & & & & & & 6,7 \\
\hline Escama & & & & & & & & & & & & & & \\
\hline Mat.Orgânica não identif. & & & & & & & & & & & & & & \\
\hline Total de estômagos & 15 & 15 & 11 & 9 & 13 & 15 & 15 & 15 & 15 & 14 & 15 & 15 & 15 & 15 \\
\hline
\end{tabular}

Revista Brasileira de Zoologia 23 (3): 779-788, setembro, 2006 


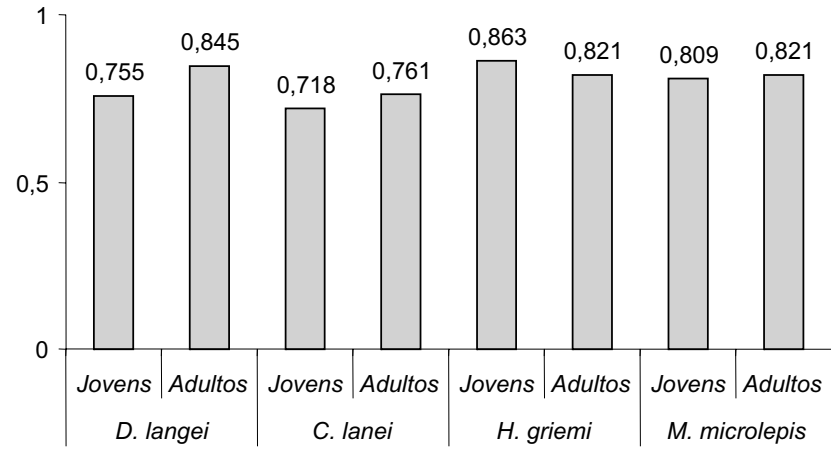

Figura 6. Amplitude do nicho de jovens e adultos de Deuterodon langei, Characidium lanei, Hyphessobrycon griemi e Mimagoniates microlepis segundo Índice de Shannon-Wiener.

mentaram com maiores freqüências de algas e detritos. Os exemplares jovens de $H$. griemi da estação outono apresentaram aproximadamente $64 \%$ de similaridade devido ao consumo de algas filamentosas (Fig. 15).

\section{Táticas alimentares}

Durante as observações, foram registrados, para as quatro espécies, comportamentos de procura, localização, captura e ingestão apenas durante o dia, principalmente durante os crepúsculos da manhã e do início da noite. Quanto a D. langei, foram observados exemplares à procura de alimento nas porções intermediárias da coluna d'água, e após a localização do alimento constatou-se que houve investida na superfície para captura de itens alóctones à deriva. Nas investidas ao fundo, os espécimes observados realizaram pastejo de algas sobre superfície rochosa. Os exemplares de C. lanei demonstraram comportamento de localização, espreita e investida sobre o alimento, principalmente larvas, ou de procura junto ao fundo de areia, sendo considerados "catadores". Os espécimes de M. microlepis foram observados na região intermediária da coluna d'água em locais rasos e junto à superfície em locais mais profundos. Ao localizar itens alóctones à deriva, houve investida e ingestão do alimento na superfície. Os exemplares de $H$. griemi buscaram recursos em todos os estratos com táticas semelhantes às de $D$. langei, porém sempre em ambientes rasos marginais sem correnteza.

\section{DISCUSSÃO}

Em geral foram observados estômagos repletos durante a primavera e o verão em jovens e adultos das quatro espécies, diferente do encontrado em um estudo realizado por Vitule \& ARANHA (2002), em que 100\% dos estômagos de uma população de $D$. langei se encontravam cheios ao longo do ano. Durante nosso estudo, D. langei e C. lanei, que dependem de itens autóctones, apresentaram maiores graus de repleção durante a primavera e verão, e as espécies que se alimentam com maior freqüência de itens alóctones, como M. microlepis e $H$ griemi, apresentaram, principalmente pelos adultos, estômagos repletos durante o outono.
Quanto à utilização dos recursos, as quatro espécies estudadas apresentaram altas amplitudes de nicho, itens alimentares com baixas freqüências, em conformidade com o descrito em MAZZoni \& Resende (2003), demonstrando pouca seletividade e grande oportunismo na escolha dos alimentos pelas espécies destes corpos d'água.

No presente estudo, ficou evidente o hábito onívoro com tendência à herbivoria de $D$. langei, corroborando estudos realizados por Aranha et al. (1998) em um riacho no Estado do Paraná. Cabe ressaltar que Deuterodon iguape Eigenmann, 1907, outra espécie do mesmo gênero, foi considerada herbívora em um estudo realizado no Estado de São Paulo por Esteves \& LobóNCerviá (2001), e onívora por Mazzoni \& Resende (2003), estudando Deuterodon sp. no Estado do Rio de Janeiro, onde os itens de origem animal na estação chuvosa e alóctones de origem vegetal na estação seca, foram significativamente predominantes. SABINo \& CASTRo (1990), definiram D. iguape como onívora, sendo algas os recursos que ocorreram com maiores freqüências na composição percentual. Entretanto, os jovens, quando analisados separadamente, apresentaram altas freqüências de insetos terrestres na dieta, ou seja, durante a ontogênese, percebeu-se que ocorre uma transição da insetivoria para onivoria, em função dos jovens apresentarem tubos digestivos proporcionalmente menores que os adultos (SABINO \& CASTRO 1990). Vitule \& Aranha (2002) constataram que, conforme o aumento no tamanho do exemplar, diminui a freqüência de itens animais e aumentam os itens de origem vegetal, embora a análise do coeficiente intestinal não tenha indicado diferença significativa no comprimento do intestino. Nosso estudo, apesar de não ter sido quantitativo, demonstra que os adultos consomem tanto vegetais superiores quanto insetos de origem alóctone em maiores proporções que os jovens.

Quanto às táticas alimentares, SABINO \& CASTRO (1990) registraram exemplares adultos de $D$. iguape apanhando folhas e frutos em meia água (drift), podando algas e catando insetos aquáticos junto ao fundo, sendo raras as investidas junto à superfície, atividade exclusiva dos jovens. Nossas observações para $D$. langei corroboram as descritas por esses autores para D. iguape, porém os adultos exploram a superfície em busca de drift com a mesma intensidade que exploram os demais estratos da coluna d' água.

Characidium lanei foi considerado insetívoro aquático (ARANHA et al. 1998, SABINo \& CASTro 1990), insetívoro (Uieda et al. 1997) e insetívoro oportunista (ArANHa et al. 2000). No presente estudo, foi observada tendência a larvofagia, conforme descrito para outras duas espécies deste gênero por CasatTi \& Castro (1998), porém foi observada entre os jovens maior plasticidade na dieta, pois além das larvas aquáticas de insetos, se alimentaram de outros organismos aquáticos, principalmente ácaros.

A tática alimentar empregada por C. lanei, segundo nossas observações, coincidem com as descritas por SABINO \& CASTRO (1990), ou seja, a espécie utilizou comportamento de espreita, investiu em pequenas presas e realizou a tática da espe-

Revista Brasileira de Zoologia 23 (3): 779-788, setembro, 2006 


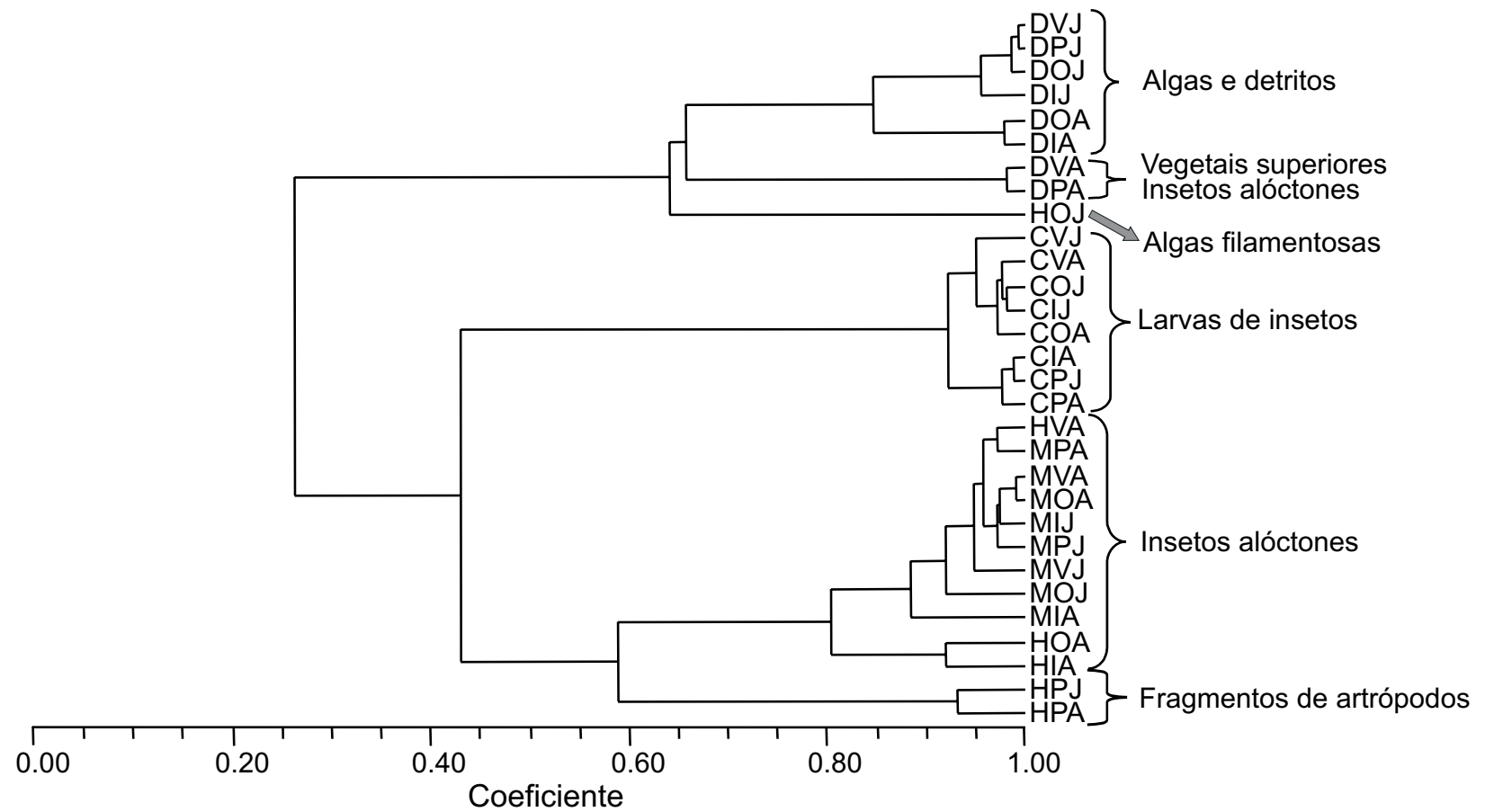

Figura 7. Dendrograma representando a similaridade da dieta entre jovens e adultos das quatro espécies: (D) D. langei, (C) C. lanei, (H) H. griemi, (M) M. microlepis. Legenda: $(V)$ verão, $(P)$ primavera, $(\mathrm{O})$ outono, (I) inverno, (J) jovens, $(A)$ adultos.

culação do substrato, porém nos estudos realizados por ARANHA et al. $(1998,2000)$, apenas o primeiro comportamento havia sido identificado.

Hyphessobrycon griemi apresentou hábito onívoro, sendo os recursos autóctones tão importantes quanto os alóctones e os itens de origem animal predominantes na dieta, principalmente dos adultos, demonstrando grande variabilidade na utilização dos recursos pelas espécies deste gênero. Nos estudos de UIEDA et al. (1997) Hyphessobrycon anisitsi Eigenmann, 1907 foi considerada insetívora-herbívora, Graciolli et al. (2003) constataram hábito onívoro para Hyphessobrycon luetkenii Boulenger, 1887, sendo os principais itens da dieta os vegetais superiores, algas e microcrustáceos e CosTA (1987) registrou freqüências altas de itens alóctones para Hyphessobrycon reticulatus Ellis, 1911. Estas variações observadas devem estar relacionadas às diferenças específicas de disponibilidade entre os ambientes estudados. Entre os Characiformes estudados, $H$. griemi parece ser a mais oportunista e com hábitos mais complexos, pois jovens e adultos apresentam, em diferentes épocas do ano, dieta semelhante às demais espécies, utilizando recursos autóctones e alóctones e capturando alimento em todos os níveis da coluna d'água. Esta plasticidade pode ser explicada em virtude dessa espécie ocupar ambientes altamente vulneráveis, como os remansos marginais, suscetíveis às variações devido às cheias e secas.

Mimagoniates microlepis é insetívora, sendo predominantes os insetos de origem alóctone em sua dieta (SABINO \& CASTRO
1990, Aranha et al. 1998, Fogaça et al. 2003, Graciolli et al. 2003, LAMPERT et al. 2003). Nossos resultados corroboram em grande parte as variações na dieta descritas por LAMPERT et al. (2003), ou seja, ausência de diferenças entre machos e fêmeas e variações entre jovens e adultos. No estudo realizado por esses autores, os jovens apresentaram altas freqüências de microcrustáceos na dieta, assim como descrito em Dufech et al. (2003), que ao compararem a dieta de duas populações de Mimagoniates rheocharis, Menezes \& Weitzman, 1990, verificaram altas freqüências de microcrustáceos em exemplares de pequeno porte. Apesar de encontrarmos altas freqüências de larvas de insetos autóctones em jovens de M. microlepis, os dados confirmam a utilização de itens autóctones nos estágios iniciais das espécies deste gênero, devido à incapacidade dos jovens de se alimentar de grandes presas como os insetos alóctones, recursos utilizados predominantemente pelos adultos.

Costa (1987), ao comparar as espécies de uma assembléia, descreve M. microlepis como a mais especializada. Em nossas observações, apesar dos indivíduos desta espécie se alimentarem predominantemente de insetos de origem alóctone, sua amplitude de nicho foi similar às demais, pois, apesar de considerada uma espécie catadora de superfície (SABINO \& CASTRO 1990, ARANHA et al. 1998), constatamos que os jovens possuem o hábito de buscar o fundo para se alimentar, capturando principalmente larvas de Diptera e microcrustáceos.

A sazonalidade encontrada no presente estudo, e descri-

Revista Brasileira de Zoologia 23 (3): 779-788, setembro, 2006 
ta em Aranha et al. (1998), Esteves \& Lobón-Cerviá (2001) e LAMPERT et al. (2003), indica que as diferenças na dieta das espécies estudadas estão relacionadas a alterações pontuais, como cheias entre outros fatores. Entretanto, alguns trabalhos realizados na região sul e sudeste do Brasil (Aranha et al. 2000, MAZzoni \& Resende 2003), discutem variações na dieta ao longo do ano, principalmente durante as cheias características do verão, que modificam a estrutura do rio, e conseqüentemente, a disponibilidade de alimento entre as estações seca e chuvosa.

Acreditamos que a grande plasticidade na utilização dos recursos alimentares pelas espécies estudadas permite a partilha dos recursos disponíveis, que ora se alimentam de recursos provenientes da floresta associada, ora se alimentam de recursos autóctones. As altas freqüências de itens alóctones encontradas na dieta demonstraram a importância da vegetação marginal como fonte de recursos, sendo fundamental para o equilíbrio desses ecossistemas e manutenção dessas comunidades, que no caso da sua supressão, ocasionaria uma pressão maior por recursos autóctones aumentando a competição intra-específica e interespecífica.

\section{AGRADECIMENTOS}

À Fundação O Boticário de Proteção à Natureza pelo apoio financeiro e logístico e ao Conselho Nacional de Desenvolvimento Científico e Tecnológico - CNPq, pela concessão da bolsa de doutorado $\mathrm{n}^{\circ}$ 142043/2001.

\section{REFERÊNCIAS BIBLIOGRÁFICAS}

Aranha, J.M.R.; D.F. Takeuti \& T. Yoshimura. 1998. Habitat use and food partitioning of the fishes in the Mergulhão stream (coastal stream of Atlantic Forest, Brazil). Revista de Biologia Tropical, San José, 46 (4): 951-959.

Aranha, J.M.R.; J.H.C. GOMES \& F.N.O. Fogaça. 2000. Feeding of two species of Characidium, C..lanei and C. pterostictum (Characidiinae) in a coastal stream of Atlantic Forest (Southern Brazil). Brazilian Archives of Biology and Technology, Curitiba, 43 (5): 527-531.

Arcifa, S.A.; T.G. Northcote \& O. Froenlich. 1991. Interactive ecology of two cohabiting characin fishes (Astyanax fasciatus and Astyanax bimaculatus) in an eutrophic Brazilian reservoir. Journal of Tropical Ecology, Cambridge, 7: 257-268.

Bicudo, C.E.M. \& R.M.T. Bicudo. 1970. Algas de águas continentais brasileiras. São Paulo, Universidade de São Paulo, 228p.

Borror, D.J. \& M.D. DeLong. 1988. Introdução ao estudo dos insetos. São Paulo, Edgard Blücher, 653p.

CasatTi, L \& R.M.C. CASTro. 1998. A fish community of the São Francisco River headwaters riffles, southeastern Brazil. Ichthyological Exploration of Freshwaters, München, 9 (3): 229-242.

CHu, H.F. 1949. The immature insects. Dubuque, W.M.C. Brown Company Publishers, 243p.
CosTA, W.J.E.M. 1984. Peixes fluviais do sistema lagunar de Maricá, Rio de Janeiro, Brasil. Atlântica, Rio Grande, 7: 65-72.

CosTA, W.J.E.M. 1987. Feeding habits of a fish community in a tropical coastal stream, rio Mato Grosso, Brazil. Studies on Neotropical Fauna and Environment, Amsterdam, 22 (3): 145-153.

Dufech, A.P.S.; M.A. Azevedo \& C.B. Fialho. 2003. Comparative dietary analysis of two populations of Mimagoniates rheocharis (Characidae: Glandulocaudinae) from two streams of Southern Brazil. Neotropical Ichthyology, São Paulo, 1 (1): 67-74.

Esteves, K.E. \& J.M.R.Aranha. 1999. Ecologia Trófica de peixes de riachos, p. 157-182. In: E.P. CaramasChi; R. Mazzoni \& P.R. Peres Neto (Eds). Ecologia de Peixes de Riachos. Rio de Janeiro, Série Oecologia Brasiliensis, PPGE-UFRJ, VI+260p.

Esteves, K.E. \& J. Lobón-Cerviá. 2001. Composition and trophic structure of a clear water Atlantic rainforest stream in southeastern Brazil. Environmental Biology of Fishes, The Hague, 62: 429-440.

FogaÇA, F.N.O.; J.M.R. Aranha, \& M.L.P. EsPer. 2003. Ictiofauna do rio do Quebra (Antonina, PR, Brasil): Ocupação espacial e hábito alimentar. Interciência, Rio de Janeiro, 28 (3): 168173.

Graciolli, G.; M.A. Azevedo \& F.A.G. De Melo. 2003. Comparative sof the diet of Glandulocaudinae and Tetragonopterinae (Ostariophysi: Characidae) in a small Stream in Southern Brazil. Studies on Neotropical Fauna and Environmental, Amsterdam, 38 (2): 95-103.

Hahn, N.S.; R. Fugi; D.Peretti; M.R. Russo \& V.E. Loureiro-Crippa. 2004. Trophic structure of the fish fauna, p. 139-143. In: A.A. Agostinho; L. Rodrigues; L.C. Gomes; S.M. Thomaz \& S.M. Miranda (Eds). Structure and functioning of the Paraná River and its floodplain. Maringá, Eduem, Nupelia, I+275p.

HoRn, H.S. 1966. Measurement of "overlap" in comparative ecological studies. The American Naturalist 100 (914): 419424.

Hyslop, E.P. 1980. Stomach contents analysis: a review of methods and their application. Journal of Fish Biology, London, 29: 411-429.

KreBS, C.J. 1989. Ecological Methodology. New York, Harper \& Row Publishers, 654p.

Lampert, V.R.; M.A. Azevedo, \& C.B. Fialho. 2003. Hábito alimentar de Mimagoniates microlepis Steindachner, 1876 (Characidae: Glandulocaudinae) do canal de ligação entre as lagoas Emboaba e Emboabinha, Rio Grande do Sul, Brasil. Comumicações do Museu de Ciências e Tecnologia, PUCRS, Porto Alegre, 16 (1): 3-16.

Lopreto, E.C. \& G. Tell. 1995. Ecossistemas de águas continentales, metodologias para su estudio. La Plata, Ediciones Sur, III+1401p.

LOWE-MCCONNELL, R.H. 1987. Ecological studies in tropical fish communities. Cambrige, University Press, XIII+382p.

Mazzoni, R. \& C.F. Resende. 2003. Seazonal diet shift a tetrago- 
nopterinae (Osteichthyes, Characidae) from the Ubatiba river, RJ, Brazil. Brazilian Journal of Biology, São Carlos, 63 (1): 69-74.

MCCafFerTy, W.P. 1981. Aquatic Entomology. Boston, Jones and Bartlett Publishers, 445p.

PÉRes, G.R. 1988. Guía para el studio de los macroinvertebrados acuáticos del Departamento de Antioquia. Bogotá, Universidad Antioquia, Faculdad de Ciências Exatas y Naturales, Centro de Investigaciones, 217p.

Resende, E.K. 2000. Trophic structure of fish assemblages in the Lower Miranda River, Pantanal, Mato Grosso do Sul State, Brasil. Revista Brasileira de Biologia, São Carlos, 60 (3): 389-403.

SABINO, J. 1999. Comportamento de peixes em riachos: métodos de estudo para uma abordagem naturalística. p. 183208. In: E.P.Caramaschi; R. Mazzoni \& P.R. Peres Neto (Eds). Ecologia de Peixes de Riachos. Rio de Janeiro, Série Oecologia Brasiliensis. PPGE-UFRJ,VI+260p.

SABINO, J. \& R.M.C. CASTRo. 1990. Alimentação, período de atividade e distribuição espacial dos peixes de um riacho da Floresta Atlântica (Sudeste do Brasil). Revista Brasileira de Biologia, São Carlos, 50 (1): 23-36.

SABINO, J. \& J. ZuANON. 1998. A stream fish assemblage in Central Amazonia: distribution, activity patterns and feeding behavior. Ichthyological Exploration of Freshwater, München, 8 (3): 201-210.

SAZIMA, I. 1986. Similarities in feeding bahaviour between some marine and freshwater fishes in two tropical communities. Journal of Fish Biology, London, 29: 53-65.

SтенR, F.W. 1987. Immature Insects. Dubuque, Kendall Hunt Publishing, vols 1 e 2, 754p e 974p.

Suguio, K. \& J. J. Bigarella. 1990. Ambientes Fluviais. Florianópolis, UFSC-UFPR, 183p.

Uieda, V.S.; P.Buzzato \& R. M. KiкUChi. 1997. Partilha de recursos alimentares em peixes em um riacho de serra do sudeste do Brasil. Anais da Academia Brasileira de Ciências, Rio de Janeiro, 69 (2): 243-252.

Vilella, F.S.; F.G. Becker \& S.M. Hartz. 2002. Diet of Astyanax species(Teleostei, Characidae) in an Atlantic Forest River in Southern Brasil. Brazilian Archives of Biology and Technology, Curitiba, 45 (2): 223-232.

Vitule, J.R.S. \& J.M.R. Aranha. 2002. Ecologia alimentar do lambari, Deuterodon langei Travassos, 1957 (Characidae, Tetragonopterinae), de diferentes tamanhos em um riacho da Floresta Atlântica, Paraná (Brasil). Acta Biológica Paranaense, Curitiba, 31 (1-4): 137-150.

Winemiller, K.O \& D.B. Jepsen. 1998. Effects of sazonality and fish movement on tropical river food webs. Journal of Fish Biology, London, 53 (A): 267-296.

ZAVALA-CAMIN, L.A. 1996. Introdução ao estudo sobre alimentação natural em peixes. Maringá, Eduem, SBI, CNPq, Nupelia, 129p.

WIENs, J.A. 1977. On competition and variable environments. American Scientitist, New Haven, 65: 590-597.

Recebido em 21.IX.2005; aceito em 24.VIII.2006. 